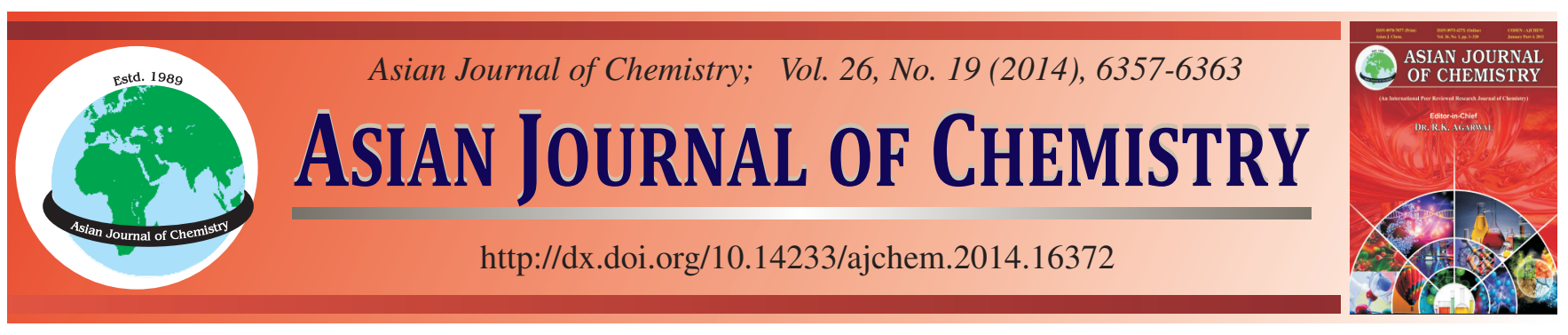

\title{
Ultrasensitive Impedimetric Lectin Biosensor with Efficient Antifouling Properties Applied in Determination of $\alpha$-Fetoprotein on Mixed Self-Assembled Monolayer on Gold
}

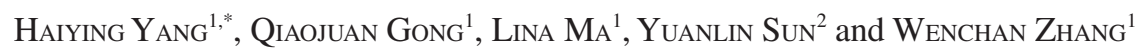

${ }^{1}$ Department of Applied Chemistry, Yuncheng University, Yuncheng 044000, P.R. China

${ }^{2}$ Department of Life Science, Yuncheng University, Yuncheng 044000, P.R. China

*Corresponding author: Fax: +86 359 2090378; Tel: +86 359 8594394; E-mail: hyyang@ycu.edu.cn

\begin{abstract}
A sensitive and attractive antifouling impedimetric lectin biosensor for the determination of $\alpha$-fetoprotein in human serum samples was developed. The biosensor was fabricated by co-assembling 11-mercapto-undecanoic acid for covalent immobilization of wheat-germ agglutinin and dithiothreitol to resist nonspecific interactions on the surface of gold electrode. In the measurement of $\alpha$-fetoprotein, the change in interfacial electron transfer resistance of biosensor was monitored using a ferri/ferrocyanide redox couple. Owing to the specific recognition of wheat-germ agglutinin with $\mathrm{N}$-glycan on $\alpha$-fetoprotein, the increase in the electron transfer resistance was linearly proportional to the logarithm of the concentration of $\alpha$-fetoprotein in the range from $1.0 \times 10^{-11}$ to $8 \times 10^{-10} \mathrm{~g} \mathrm{~mL}^{-1}$ and a detection limit of $9 \times 10^{-12} \mathrm{~g} \mathrm{~mL}^{-1} \alpha$-fetoprotein was achieved. The fabricated biosensor allowed direct quantification of extrinsic $\alpha$-fetoprotein in serum samples. This work provides a promising strategy for clinical application with impressive sensitivity and antifouling characteristics.
\end{abstract}

Keywords: Impedimetric, Lectin biosensor, Mixed self-assembled monolayer, $\alpha$-Fetoprotein.

\section{INTRODUCTION}

Development of simple, sensitive and selective method for the determination of specific proteins in complex biological matrices such as blood plasma or serum has received more and more attention in clinical and biological fields ${ }^{1}$. Glycosylation is one of the most common modifications to proteins and its presence affects protein-protein interactions, cell-cell recognition, adhesion and motility ${ }^{2}$. Mounting evidence suggests that glycosylation is altered in disease states such as cancer and associated with disease development ${ }^{3}$. Most clinical biomarkers are glycoproteins. Therefore, analysis of glycobiomarkers is expected to improve the specificity of disease diagnosis. Biosensors are simple, inexpensive analytical devices and provide escalating quantities of proteins information ${ }^{4}$. Extensive efforts have been devoted to the design of novel biosensors for glycobiomarkers detection, including the employment of novel biological recognition molecules as well as highly sensitive detection techniques, such as electrogenerated chemiluminescence immunoassay ${ }^{5,6}$ and electrochemical immunoassay ${ }^{7-13}$ and fluorescence immunoassay ${ }^{14}$. Despite the extensive development of these methods, the antibodies that are widely used have some limitations such as the challenging production of antibodies in vivo ${ }^{15}$. Approaches based on lectin open an avenue for analysis of glycans on biomarkers. Taken as molecular recognition elements, lectins can strongly bind to specific carbohydrate moieties on the surface of glycoproteins, have received considerable interest due to the advantages, such as easy production and intrinsic stability compared with antibodies ${ }^{16}$. Compared with antibody-based immunoassay, the lectin-based bioassay could detect the protein content and discriminate the aberrant glycosylation of the tumour biomarkers, which could increase the specificity for cancer diagnosis since the aberrant glycosylation is a fundamental characteristic of progression of cancer ${ }^{17,18}$.

As a result, a lot of lectin-based assays for the detection and discrimination the glycan expression of glycoproteins have been proposed in the past few years, such as mass spectrometry $^{19}$, fluorescence ${ }^{20}$, electrochemistry ${ }^{21,22}$ and electrochemiluminescent ${ }^{23}$, etc. Most reported methods are based on a labeling (analytes or recognition elements) strategy, which not only requires a complicated labeling procedure but also reduces the bioaffinity of the recognition elements. Electrochemical technique, especially electrochemical impedance spectroscopy (EIS) technique, becomes increasingly popular in a variety of protein biosensing because it offers several advantages such as simplicity, high sensitivity and serving as an elegant way to interface biorecognition events and signal 
transduction $^{24}$. Various EIS lectin-based sensors have been designed for determination of biomarkers or cancer cells. Oliverira et al. ${ }^{25}$ reported a biosystem to analyze the interactions between CramoLL lectin and fetuin for the detection of glycoprotein in the serum of patients contaminated with dengue serotypes 1, 2 and 3. Belle et al. ${ }^{22}$ developed a label-free EIS method for the detection of glycan-lectin interactions by immobilizing lectins of Sambucus nigra agglutinin and peanut agglutinin on layered $\mathrm{Cu} / \mathrm{Ni} / \mathrm{Au}$ printed circuit board electrodes. The effort is mainly focused on the improvement of sensitivity by employing various amplification strategies and reducing background strategies ${ }^{26}$. However, these strategies are largely limited due to the challenge of the interference of nonspecific binding and a high background ${ }^{27}$. Therefore, how to specifically and sensitively recognize target protein in the presence of non-target proteins is a key problem in the clinical bioassay ${ }^{28}$.

To tackle the specificity issues, several approaches have been developed and reported. Surface modifications with an antifouling mixed self-assembled monolayer and polymer brushes were employed to reduce or suppress the non-specific adsorption. For example, mixed self-assembled monolayer of alkane thiolates on gold to reduce the nonspecific adsorption of undesired biological entities ${ }^{29,30}$. The incorporation of both thiols in a mixed self-assembled monolayer enables the attachment of receptor molecules and induces specific interaction of the immobilized molecules instead of a nonspecific adsorption of undesired biospecies on the surface ${ }^{31}$. Qi et al..$^{29}$ reported an EIS apta sensor by co-assembling anti-thrombin binding aptamer and dithiothreitol, followed by assembling of 6-mercapto-1-hexanol on the surface of gold electrode to form a ternary monolayer to determinate of thrombin and the mixed self-assembled monolayer offered high sensitivity and direct measurement thrombin in undiluted serum with good antifouling characteristics. Lieven et al. ${ }^{32}$ reported an immunoassay for prostate-specific antigen based on a mixed self-assembled monolayer to minimize non-specific adsorption of analyte.

With the foregoing analysis in mind, in this paper, we describe a simple, selective and sensitive impedimetric lectin biosensor for the determination of protein in diluted serum sample using the lectin wheat-germ agglutinin as the recognition element. $\alpha$-Fetoprotein, a tumor marker for hepatocellular carcinoma which contains one $\mathrm{N}$-glycosylation site at asparagine 232, was chosen as model protein in this work ${ }^{17}$. Schematic representation of biosensor with fabrication steps and performance is showed in Scheme-I. The biosensor was designed by co-assembling 11-mercapto-undecanoic acid available for covalent immobilization of lectin and dithiothreitol forming an interfacial layer blocking nonspecific interactions on the surface of gold electrode to form a binary monolayer. The introduction of target $\alpha$-fetoprotein forming a wheat-germ agglutinin-carbohydrate conjugate increased electron transfer resistance of biosensor. The characteristics and analytical performance of the wheat-germ agglutinin biosensor for the detection of $\alpha$-fetoprotein are reported. The fabricated biosensor was also applied to detect $\alpha$-fetoprotein in both buffer solution and diluted serum sample.

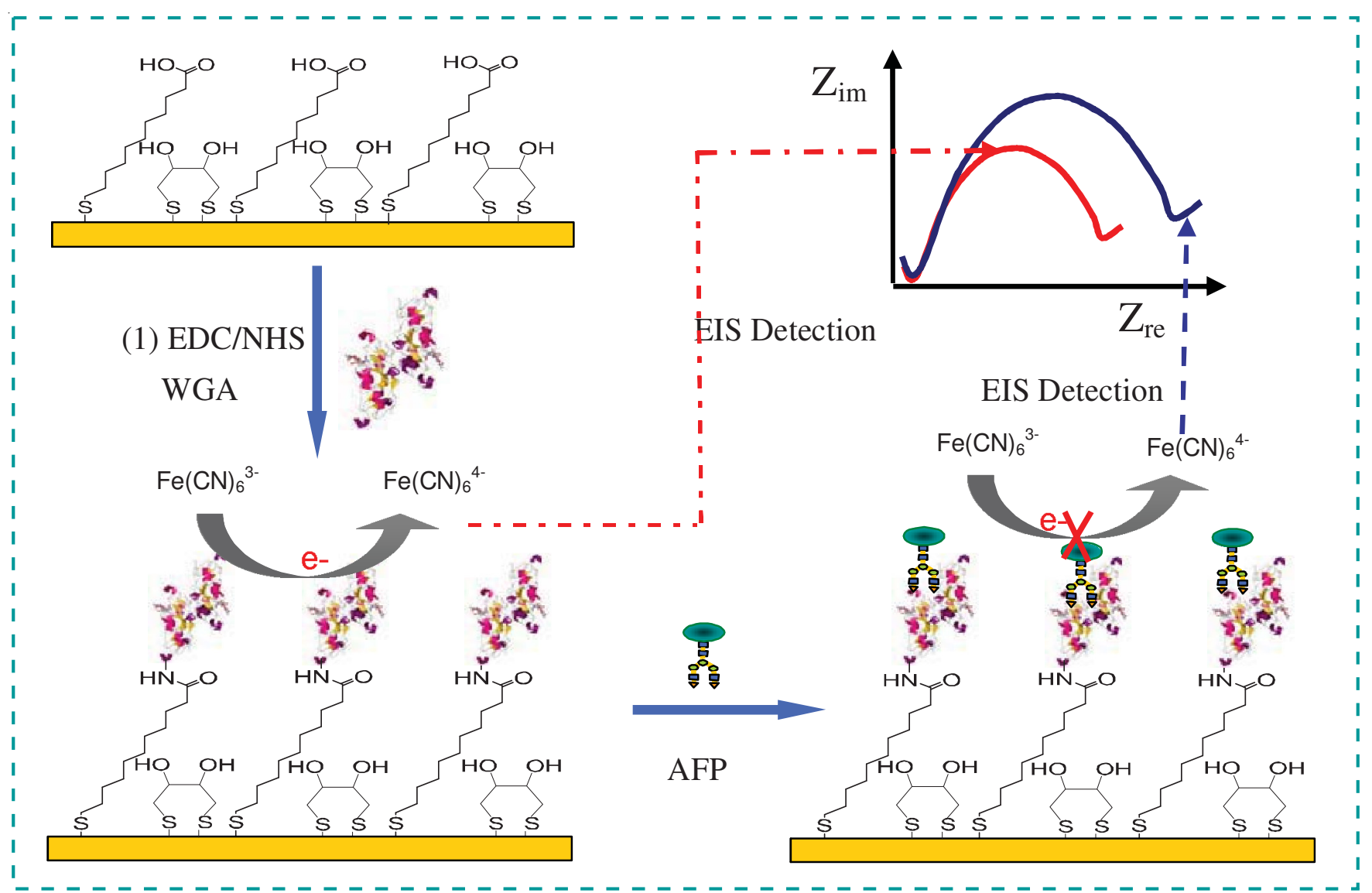

Scheme-I: Schematic representation of the fabrication of wheat-germ agglutinin biosensor and detection of $\alpha$-fetoprotein 


\section{EXPERIMENTAL}

Wheat-germ agglutinin (wheat-germ agglutinin, from Triticum vulgarist), mannose, galactose, $\mathrm{N}$-acetylglucosamine (GlcNAc), N-acetylgalctosamine (GalNAc), 11-mercaptoundecanoic acid, 6-mercapto-1-hexanol, dithiothreitol, N-(3dimethylamino-propy)- $N$ '-ethylcarbodimide hydrochloride (EDC), N-hydroxy-succinimide (NHS) were obtained from Sigma-Aldrich (St. Louis, USA). Human $\alpha$-fetoprotein (AFP, M803209) was obtained from Fitzgerald Industries International, Inc. (USA). Bovine serum albumin (BSA) was obtained from Sinopharm Chemical Reagent Co., Ltd. (China). All reagents were of analytical grade and used as received. Millipore Milli$\mathrm{Q}$ water $(18.2 \mathrm{M} \Omega \mathrm{cm})$ was used to prepare all the solutions.

$10 \mathrm{mM}$ phosphate buffer saline (PBS, pH 7.4, $10 \mathrm{mM}$ $\mathrm{Na}_{2} \mathrm{HPO}_{4} / \mathrm{NaH}_{2} \mathrm{PO}_{4}$ and $100 \mathrm{mM} \mathrm{NaCl}$ ) was used as lcetin immobilization buffer. $10 \mathrm{mM}$ PBS (pH 7.4) was used as washing buffer. $10 \mathrm{mM}$ PBS containing $1 \mathrm{mM} \mathrm{CaCl}_{2}$ and $1 \mathrm{mM}$ $\mathrm{MnCl}_{2}$ was used as binding buffer. $\alpha$-Fetoprotein solutions and all carbohydrate solutions (mannose, galactose, GlcNAc and GalNAc) were prepared by binding buffer.

A CHI 660 electrochemical workstation (Shanghai Chenhua Instrument Co. Ltd., Shanghai, China) was used for all electrochemical measurements. All experiments were carried out using a conventional three-electrode system with a fabricated lectin biosensor or a gold electrode as working electrode, a platinum wire as counter electrode and an $\mathrm{Ag} / \mathrm{AgCl}$ (sat. $\mathrm{KCl})$ as reference electrode. The gold electrode (2 mm diameter) was polished to a mirror finish using 0.3 and 0.05 $\mu \mathrm{m}$ alumina slurry (Beuhler) followed by thorough rinsing with water and drying under flowing nitrogen gas. All potentials were referred to this reference electrode.

Fabrication of biosensor: A cleaned gold electrode was immersed into $100 \mu \mathrm{L}$ solution of $1 \mu \mathrm{M} 11$-mercaptoundecanoic acid and $10 \mu \mathrm{M}$ dithiothreitol, then incubated $14 \mathrm{~h}$ at $4{ }^{\circ} \mathrm{C}$ in a humidified chamber to obtain the DTT/MUA/Au electrode. The substrates were thoroughly rinsed with washing buffer and dried under a stream of nitrogen. After washing the DTT/MUA/Au was activated in $100 \mu \mathrm{L}$ of freshly prepared solution containing $2 \mathrm{~g} \mathrm{~L}^{-1} \mathrm{EDC}$ and $5 \mathrm{~g} \mathrm{~L}^{-1} \mathrm{NHS}$ for $0.5 \mathrm{~h}$ and rinsed with washing buffer. The activated electrode was then immersed into $100 \mu \mathrm{L}$ of $1 \mathrm{~g} \mathrm{~L}^{-1}$ wheat-germ agglutinin for $1 \mathrm{~h}$ at $-25{ }^{\circ} \mathrm{C}$. Finally, the wheat-germ agglutinin biosensor (WGA/DTT/MUA/Au) was obtained. The EIS biosensor was rinsed with washing buffer and stored at $4{ }^{\circ} \mathrm{C}$ in the dark.

Serum samples preparation: $\alpha$-Fetoprotein serum samples were prepared by adding small volume of extrinsic $\alpha$-fetoprotein solution in excess volume of diluted serum samples. The healthy human serum samples were from local hospital. Blood samples serum were transferred into separate tubes and stored at $-20{ }^{\circ} \mathrm{C}$. Before analyses, the human serum samples were diluted by biding buffer. In the case of the serum samples analysis, the blank assays corresponded to the serum sample without added extrinsic $\alpha$-fetoprotein and the recovery experiments prepared by adding small volume of extrinsic $\alpha$ fetoprotein solution in excess volume of diluted serum samples.

Electrochemical measurement: The fabricated biosensor was immersed in $100 \mu \mathrm{L}$ of $10 \mathrm{mM}$ PBS containing different concentrations of $\alpha$-fetoprotein or serum samples for $60 \mathrm{~min}$ and then rinsed with washing buffer. Electrochemical measurements were carried out in $3 \mathrm{~mL}$ of $10 \mathrm{mM}$ PBS containing $5 \mathrm{mM} \mathrm{K}_{4} \mathrm{Fe}(\mathrm{CN})_{6}$ and $5 \mathrm{mM} \mathrm{K}_{3} \mathrm{Fe}(\mathrm{CN})_{6}$ at the equilibrium potential of $[\mathrm{Fe}(\mathrm{CN}) 6]^{3-/ 4-}(0.24 \mathrm{~V}$ vs. $\mathrm{Ag} / \mathrm{AgCl})$ with a $5 \mathrm{mV}$ sinusoidal excitation amplitude. The impedance spectra were recorded within a frequency range from $100 \mathrm{KHz}$ to $1 \mathrm{~Hz}$ with a sampling rate of 12 points per decade. The concentration of $\alpha$-fetoprotein was quantified by an increase in the electron transfer resistance $\Delta \mathrm{R}_{\mathrm{et}}\left(\Delta \mathrm{R}_{\mathrm{et}}=\mathrm{R}_{\mathrm{et.i}}-\mathrm{R}_{\mathrm{et.} .0}\right)$, where $\mathrm{R}_{\mathrm{et} .0}$ and $\mathrm{R}_{\mathrm{et.i}}$ are the electron transfer resistance values before and after incubation with $\alpha$-fetoprotein, respectively. All electrochemical experiments were carried out at room temperature $\left(25 \pm 1{ }^{\circ} \mathrm{C}\right)$.

\section{RESULTS AND DISCUSSION}

The different electrodes in the fabrication of the wheatgerm agglutinin biosensor were characterized by electrochemical impedance spectrometry and cyclic voltammetry in the presence of the ferri/ferrocyanide redox couple as redox probe. As shown in Fig. 1a, the $R_{\text {et }}$ measured was $300 \Omega$ for Au electrode and $4957 \Omega$ for the DTT/MUA/Au (curve a and curve $b$ ), $9304 \Omega$ for the WGA/DTT/MUA/Au (curve c). The $\mathrm{R}_{\mathrm{et}}$ continued to increase to $17050 \Omega$ (curve d) after $5 \times 10^{-11} \mathrm{~g} \mathrm{~mL}^{-1} \alpha$ fetoprotein incubating with wheat-germ agglutinin immobilized on the surface of gold electrode. It can be also seen from Fig. $1 b$ that when the wheat-germ agglutinin is immobi lized and $\alpha$ fetoprotein is captured by the biosensor, the current decreased. This is mainly attributed to the fact that the big protein immobilized on the surface of the electrode prohibits the mass transfer of $\left[\mathrm{Fe}(\mathrm{CN})_{6}\right]^{3-/ 4-}$ from the solution to the surface of electrode. The results indicate that wheat-germ agglutinin is modified onto a DTT/MUA platform by the carboxylic groups of 11-mercapto-undecanoic acid which are activated for wheatgerm agglutinin coupling with EDC and NHS and wheat-germ agglutinin can specifically recognize the GlcNAc fragment of $\mathrm{N}$-glycan on $\alpha$-fetoprotein ${ }^{33,34}$.

In the fabrication of biosensor, the interfacial properties of the mixed monolayer play an important role in the analytical performance of biosensor ${ }^{32}$. It is reported that the mixed selfassembled monolayer with antifouling characters were employed to reduce or suppress the non-specific adsorption. As to estimate the degree of non-specific binding of the fabricated biosensor, non-carbohydrate protein BSA was chosen as nonspecific protein, which would not be recognized by wheatgerm agglutinin. After incubated with $0.1 \% \mathrm{BSA}$, the $\mathrm{R}_{\mathrm{et}}$ value increases only $5.2 \%$ for the mixed binary layer indicted that the inclusion of dithiothreitol during wheat-germ agglutinin immobilization can highly effectively prevent nonspecific adsorption of BSA. Dithiothreitol is a four carbon $\alpha-\omega$ dithiol with hydroxyl groups on the second and third carbons. The two hydroxyl groups on dithiothreitol exposed at molecule outer surface provide a hydrophilic microenvironment which is favourable for binding reaction and which also enhances the antifouling properties of the monolayer ${ }^{29,35}$.

Optimization of ratio of mixed self-assembled monolayer and wheat-germ agglutinin concentration: Experimental parameters including the ratio of mixed self-assembled monolayer during fabrication and the incubation time were optimized. As expected, at a fixed immobilization time, the ratio 

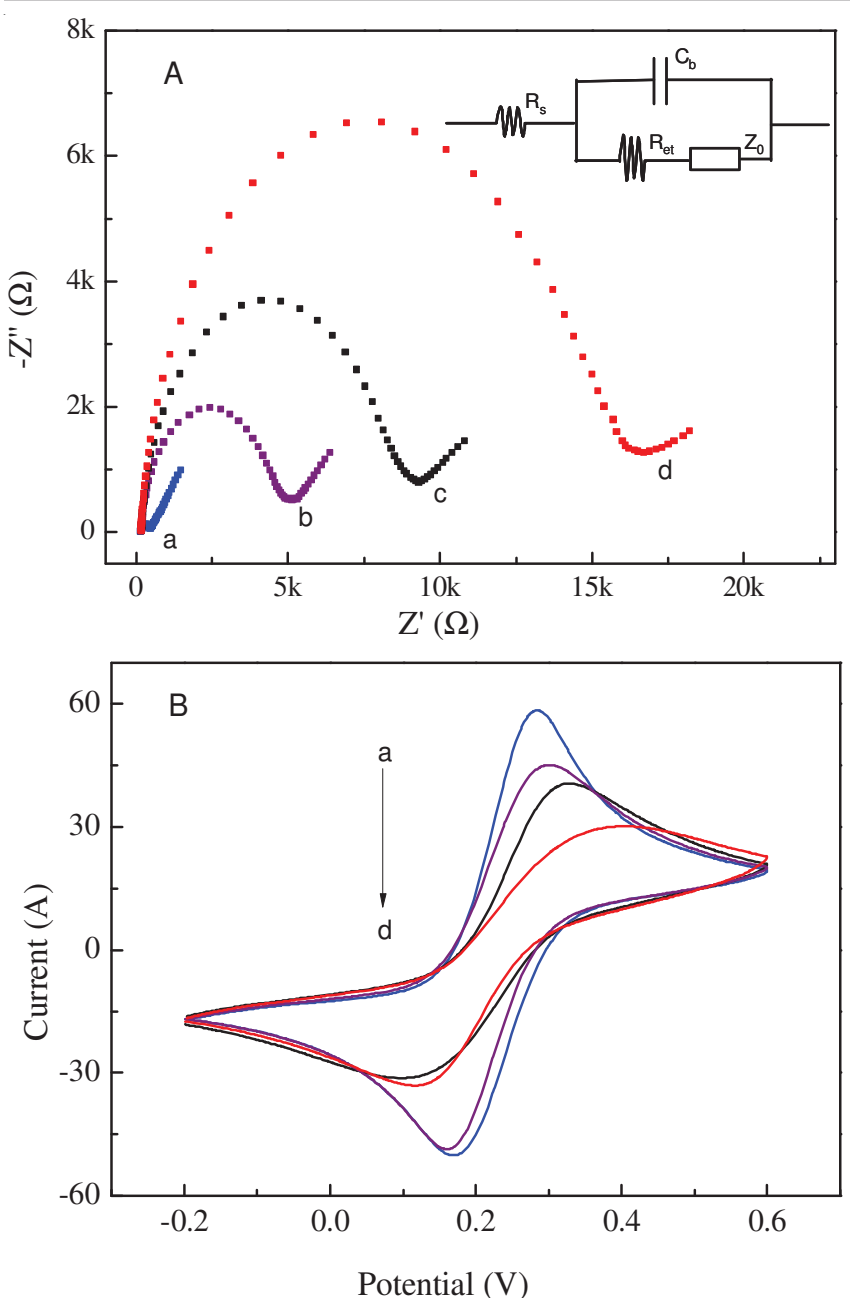

Fig. 1. (A) Nyquist plots and (B) cyclic voltammetry obtained in $10 \mathrm{mM}$ PBS (pH 7.4 ) containing $5 \mathrm{mM} \mathrm{K}_{3}\left[\mathrm{Fe}(\mathrm{CN})_{6}\right] / 5 \mathrm{mM} \mathrm{K}_{4}\left[\mathrm{Fe}(\mathrm{CN})_{6}\right]-$ $0.1 \mathrm{M} \mathrm{KCl}$ at (a) a bare gold electrode, (b) DTT/MUA/Au, (c) WGA/ DTT/MUA/Au, (d) WGA/DTT/MUA/Au after incubation with $5 \times$ $10^{-11} \mathrm{~g} \mathrm{~mL}^{-1} \alpha$-fetoprotein for $60 \mathrm{~min}$. The biased potential was $0.24 \mathrm{~V} v s$. Ag/AgCl. The frequency was from $1 \mathrm{~Hz}$ to $100 \mathrm{kHz}$ and the amplitude was $5 \mathrm{mV}$ for EIS. The insert in (a) was the equivalent circuit. Scan rate in cyclic voltammetry was $100 \mathrm{mv} \mathrm{s}^{-1}$

of mixed alkane thiolates directly influences the surface coverage of the recognition element on the DTT/MUA/Au and further affects the sensitivity of the biosensor. The performance of the biosensor was tested on five different surfaces prepared from a mixture of MUA/DTT having different molar rations in a liquid phase (1:0, 1:0.5, 1:1, 1:10, 1:30, 1:50). 11-mercaptoundecanoic acid carries a functional group to covalently immobilize the recognition molecule, whereas dithiothreitol minimizes non-specific adsorption. Different levels of wheatgerm agglutinin immobilization could be achieved by varying the amounts of 11-mercapto-undecanoic acid and dithiothreitol used to prepare the mixed self-assembled monolayer solution (expressed in $\mathrm{n} / \mathrm{n}$ ratios). Fig. $2 \mathrm{~b}$ shows the influence of different ration of MUA/DTT on the normalized EIS values (S/N $=\Delta \mathrm{R}_{\mathrm{e}} / \mathrm{R}_{\mathrm{et}, 0}$ ) with $1 \mathrm{~g} \mathrm{~L}^{-1}$ wheat-germ agglutinin immobilization for the biosensor fabrication. After the recognition molecular immobilization, the biosensor incubated with $5 \times 10^{-11} \mathrm{~g} \mathrm{~mL}^{-1}$ and $5 \times 10^{-10} \mathrm{~g} \mathrm{~mL}^{-1} \alpha$-fetoprotein, respectively. Apparently, incubation with $\alpha$-fetoprotein, the normalized EIS values increase as the ratio increases from 1:0 to 1:10 and then decreased with ratios from 1:10 to 1:50. The highest signal was achieved on the 1:10 MUA/DTT mixed self-assembled monolayer. Since the carboxylic groups on the 1:10 11-mercapto-undecanoic acid mixed self-assembled monolayer are less imbedded in its two-dimensional structures compared to a 1:0 MUA/DTT monolayer, they are believed to be more accessible for immobilization $^{32}$. This could explain the high immobilization degree observed on the 1:10 MUA/DTT mixed self-assembled monolayer. The results show clearly that the steric crowding of recognition molecular immobilization at the electrode surface inhibits the interaction between lectin and carbohydrate ${ }^{36}$. Therefore, a 1:10 ratio of the MUA/DTT was chosen in the following experiments.

Fig. $2 b$ shows the influence of incubation time on the $\mathrm{R}_{\mathrm{et}}$ values when the biosensors are incubated with $5 \times 10^{-11} \mathrm{~g} \mathrm{~mL}^{-1}$ $\alpha$-fetoprotein. The values increase sharply as the incubation time increases from 5 to $40 \mathrm{~min}$ and reach a plateau at $60 \mathrm{~min}$. This result compares favourably to the incubation time of 60 min between wheat-germ agglutinin immobilized on singlewalled carbon nanoborns modified glass carbon electrode and the carbohydrates of cancer cells for an EIS biosensor ${ }^{21}$. This
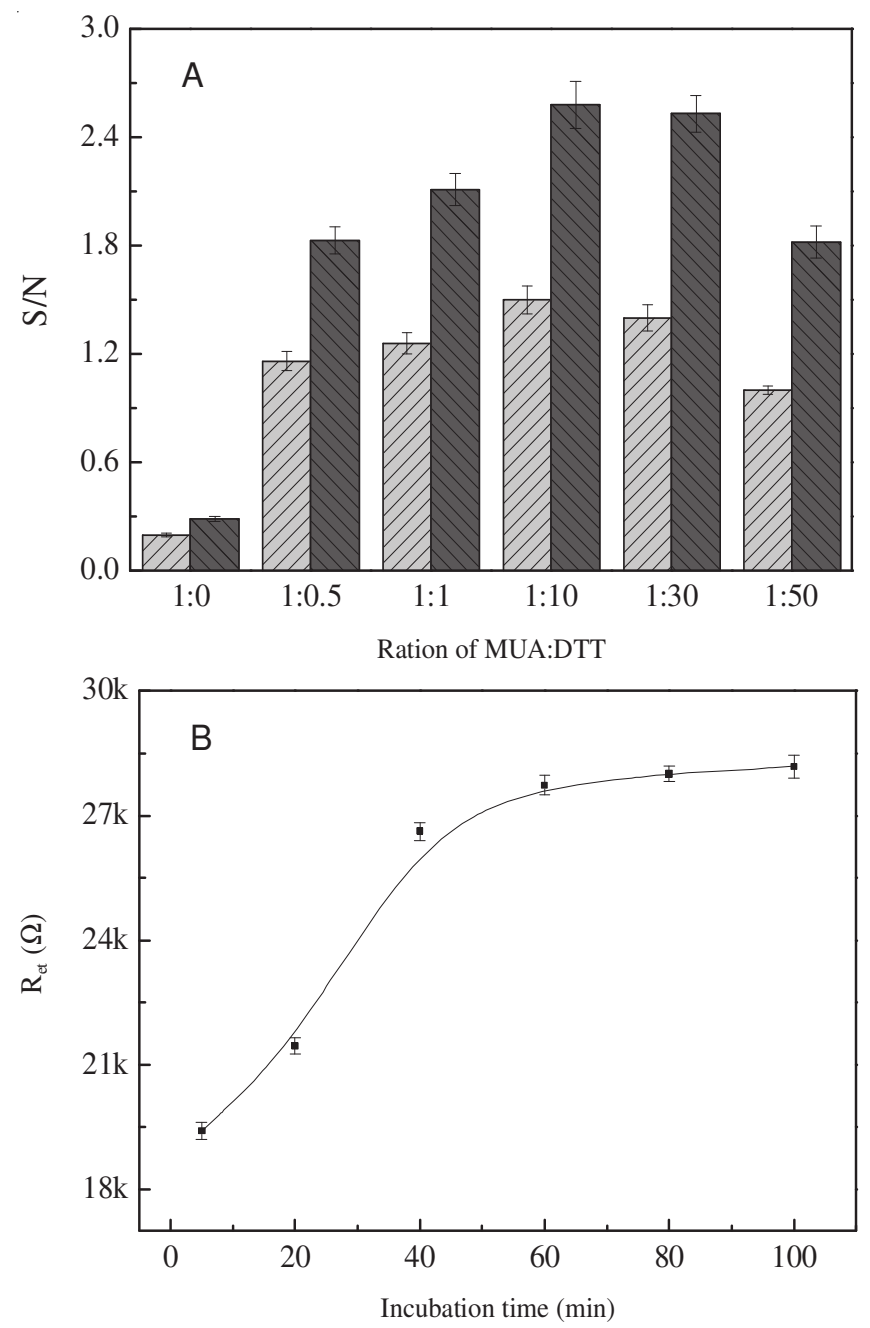

Fig. 2. (A) Dependence of the normalized EIS signal on the ration of MUA:DTT after the biosensor incubation with $5 \times 10^{-11} \mathrm{~g} \mathrm{~mL}^{-1} \alpha$ fetoprotein (light gray column) and $5 \times 10^{-10} \mathrm{~g} \mathrm{~mL}^{-1} \alpha$-fetoprotein (dark gray column) for $60 \mathrm{~min}$, (B) Dependence of $\mathrm{R}_{\mathrm{et}}$ on incubation time for $5 \times 10^{-11} \mathrm{~g} \mathrm{~mL}^{-1} \alpha$-fetoprotein. EIS measurement condition was the same as in Fig. 1 
finding suggests that binding proceeded quickly and completed in $1 \mathrm{~h}$. To ensure efficient binding while using a short incubation time, an incubation time of $1 \mathrm{~h}$ was chosen for the following experiments.

Analytical performance of the biosensor: The quantitative behaviour of the wheat-germ agglutinin biosensor was assessed by measuring the dependence of $\Delta \mathrm{R}_{\mathrm{et}}$ on the concentration of $\alpha$-fetoprotein under the optimized conditions. Fig. 3 shows Nyquist plots of the faradic impedance spectra for the biosensor with different concentrations of $\alpha$-fetoprotein.

The inset of Fig. 3 shows the logarithmic relationship between $\Delta \mathrm{R}_{\mathrm{et}}$ and the concentration of $\alpha$-fetoprotein in the range of $1 \times 10^{-11} \mathrm{~g} \mathrm{~mL}^{-1}$ to $8 \times 10^{-10} \mathrm{~g} \mathrm{~mL}^{-1}$. The regression equation was $\Delta \mathrm{R}_{\mathrm{et}}=16023 \lg \mathrm{C}+183391\left(\mathrm{C}\right.$ is in units of $\left.\mathrm{g} \mathrm{mL}^{-1}\right)$ with a regression coefficient of 0.9727 . The detection limit was $9 \times$ $10^{-12} \mathrm{~g} \mathrm{~mL}^{-1}\left(9 \mathrm{pg} \mathrm{mL}^{-1}\right) \alpha$-fetoprotein $(\mathrm{S} / \mathrm{N}=3)$. This detection limit is lower than those of previously reported biosensors such as the electrochemical immunosensor based on graphene sheet and multienzyme functionalized carbon nanospheres $(10 \mathrm{pg}$ $\left.\mathrm{mL}^{-1}\right)^{12}$ and the electrochemical immunosensor based on an electrochemically addressing method for the fabrication of an immunosensor $\left(0.02 \mathrm{ng} \mathrm{mL}^{-1}\right)^{10}$. However, the detection limit is slightly higher than the $0.5 \mathrm{pg} \mathrm{mL}^{-1}$ reported for an electrochemical immunoassay based on target-induced release of biomolecules from magnetic carbon nanotubes ${ }^{12}$.

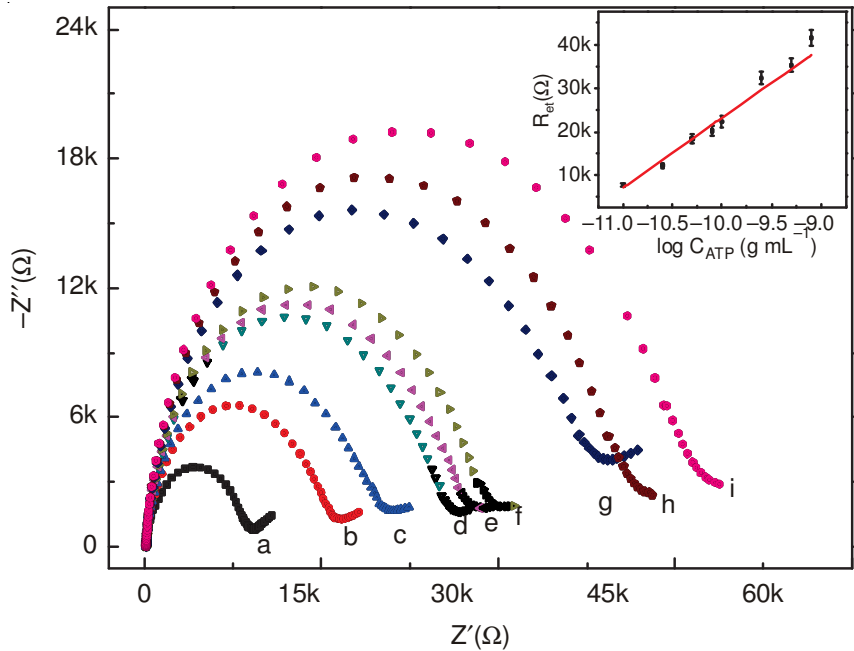

Fig. 3. Nyquist plots of impedance spectra of the biosensor for different concentrations of a-fetoprotein. (a) $0 \mathrm{~g} \mathrm{~mL}^{-1}$; (b) $1 \times 10^{-11} \mathrm{~g} \mathrm{~mL}^{-1}$; (c) $2.5 \times 10^{-11} \mathrm{~g} \mathrm{~mL}^{-1}$; (d) $5 \times 10^{-11} \mathrm{~g} \mathrm{~mL}^{-1}$; (e) $8 \times 10^{-11} \mathrm{~g} \mathrm{~mL}^{-1}$; (f) 1 $\times 10^{-10} \mathrm{~g} \mathrm{~mL}^{-1}$; (g) $2.5 \times 10^{-10} \mathrm{~g} \mathrm{~mL}^{-1}$; (h) $5 \times 10^{-10} \mathrm{~g} \mathrm{~mL}^{-1}$; (i) $8 \times$ $10^{-10} \mathrm{~g} \mathrm{~mL}^{-1}$. Inset: Dependence of $\Delta \mathrm{R}_{\mathrm{et}}$ on the logarithm of $\alpha$-fetoprotein concentration. EIS measurement condition was the same as in Fig. 1

The reproducibility of the biosensor was estimated for the detection of $5 \times 10^{-11} \mathrm{~g} \mathrm{~mL}^{-1} \alpha$-fetoprotein. The relative standard deviation obtained was $3.6 \%$ using five individual biosensors and was $4.7 \%$ for seven independent measurements using the same biosensor. This indicates that the reproducibility of the fabricated biosensors is feasible. The storage stability of the biosensor was also examined. After stored at $4{ }^{\circ} \mathrm{C}$ in 10 mM PBS ( $\mathrm{pH} 7.4$ ) for 1 week, the biosensor showed that the average EIS value was $96.3 \%$ of initial EIS value for $5 \times 10^{-11}$ $\mathrm{g} \mathrm{mL} \mathrm{m}^{-1} \alpha$-fetoprotein.
Evolution of the selectivity of the biosensor: In an attempt to evaluate the selectivity of the biosensor, a panel of carbohydrates was tested, including the specific binding carbohydrate (GlcNAc) and nonspecific carbohydrates (galactose, mannose, glucose and GalNAc) ${ }^{37}$. The results are shown in Fig. $4 a . \Delta R_{\mathrm{et}} / \mathrm{R}_{\mathrm{et}, 0}$ was 0.93 for GlcNAc. In stark contrast, $\Delta \mathrm{R}_{\mathrm{et}} / \mathrm{R}_{\mathrm{et}, 0}$ was only 0.07 for galactose, 0.14 for GalNAc, $0.13,0.12$ for mannose and glucose, respectively. These results indicate that the fabricated wheat-germ agglutinin biosensor can response to GlcNAc, which is attributed to the fact that wheat-germ agglutinin contains eight putative carbohydrate-binding sites for GlcNAc based on the principle binding domain of the aromatic residues stacking with the sugar, as well as the helper domain through hydrogen bonding ${ }^{38}$. This indicates that the designed lectin biosensor has a high selectivity might be ascribed to the antifouling monolayer.

The binding constant $\left(\mathrm{K}_{\mathrm{b}}\right)$ of the immobilized wheat-germ agglutinin and GlcNAc was also determined using the proposed EIS method ${ }^{39}$ to further understand the lectin-carbohydrate interactions. The $\mathrm{K}_{\mathrm{b}}$ was calculated to be $1.60 \times 10^{8} \mathrm{M}^{-1}$ from the plot of [GlcNAc] $/ \Delta \mathrm{R}_{\mathrm{et}}$ as a function of [GlcNAc], representing a Langmuir isotherm adsorption (Fig. 4b). This value is
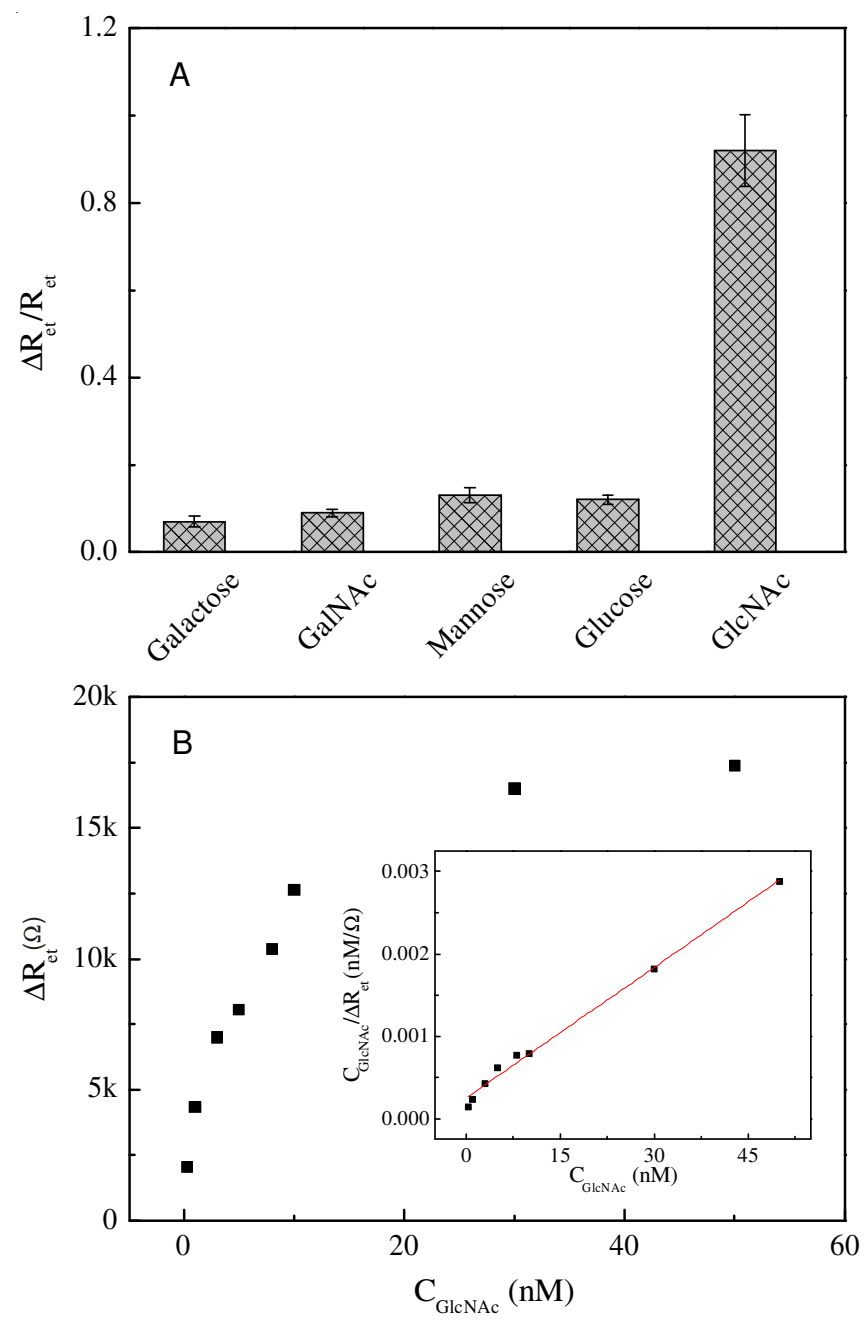

Fig. 4. (A) The normalized EIS responses of the biosensor to carbohydrates; (B) Langmuir isotherms obtained from the biosensor after incubation with different concentrations of GlcNAc. Inset in B: linear regression between $\mathrm{c}_{\mathrm{GlcNAd}} / \Delta \mathrm{R}_{\mathrm{et}}$ and $\mathrm{c}_{\mathrm{GlcNAc}}$. The concentration of carbohydrates was $1 \times 10^{-9} \mathrm{M}$. The incubation time was $60 \mathrm{~min}$. EIS measurement condition was the same as in Fig. 1 
slightly higher than the $4.82 \times 10^{7} \mathrm{M}^{-1}$ calculated by surface plasmon resonance for wheat-germ agglutinin and monomeric GlcNAc $^{40}$. This large $\mathrm{K}_{\mathrm{b}}$ value suggests that the binding strength between GlcNAc and surface-confined wheat-germ agglutinin is significantly strong.

Electrochemical detection of $\boldsymbol{\alpha}$-fetoprotein in serum samples: Furthermore, the application potential of the lectin biosensor was tested for the analysis of $\alpha$-fetoprotein from both healthy individuals and liver cancer patients. The dilution of human serum was important in order to detect glycoproteins with high sensitivity and at the same time, lowering the effect of nonspecific interactions from such complex samples. A dilution of the human serum samples 1:1000 was used as reported by Bertok et al. ${ }^{41}$. A measurable blank signal was observed when incubated with serum diluted 1:1000, showing only 5.6 $\%$ increase in $\mathrm{R}_{\mathrm{et}}$ values in comparison to that of the biosensor incubated with buffer solution and the similar results were also obtained in Reference ${ }^{41}$. Although some blank signal was observed, the impendence was also increased with increase of concentration of extrinsic $\alpha$-fetoprotein and the $\mathrm{R}_{\mathrm{et}}$ has a fine linear relationship with the logarithm of the concentration of $\alpha$-fetoprotein from $6 \times 10^{-12} \mathrm{~g} \mathrm{~mL}^{-1}$ to $6 \times 10^{-10} \mathrm{~g} \mathrm{~mL}^{-1}$. The regression equation was $\Delta \mathrm{R}_{\mathrm{et}}=14017 \mathrm{lg} \mathrm{C}+163176(\mathrm{C}$ is in units of $\mathrm{g} \mathrm{mL}^{-1}$ ) and regression coefficient was 0.9635 . The detection limit for $\alpha$-fetoprotein was $8 \mathrm{pg} \mathrm{mL}^{-1}$, which is slightly lower than that of buffer solution. This may be due to the unspecific affinity of substances in the biological samples ${ }^{42}$. The performance of the wheat-germ agglutinin biosensor was further validated by standard addition of $\alpha$-fetoprotein to human serum diluted $1: 1000$. The results showed a recovery of $103.3 \pm 3.7 \%$ which was calculated based on the calibration curve as shown in Tabel-1. The results based on the recovery clearly indicate a feasibility of the EIS assay in the clinical sample. This shows that the designed lectin biosensor has a satisfied performance which might be ascribed to the antifouling characteristic of the mixed self-assembled monolayer. Further experiments are needed to see if the fabricated lectin biosensor can be applied for the analysis of the severity of liver cancer from glycoprofiling of human serum by incorporating different lectins. In order to achieve this goal, the signal from the lectin biosensor has to be correlated with standard clinical methods, which is currently under way.

\begin{tabular}{lcccc}
\multicolumn{5}{c}{ TABLE-1 } \\
& $\begin{array}{c}\text { ANALYTICAL RESULTS FOR DIFFERENT } \\
\text { HEALTHY SERUM SAMPLES }(\mathrm{n}=5)\end{array}$ \\
\hline SAMPLE & $\begin{array}{c}\text { AFP added } \\
\left(\times 10^{-10} \mathrm{~g}\right. \\
\left.\mathrm{mL}^{-1}\right)\end{array}$ & $\begin{array}{c}\text { AFP found } \pm \text { SD } \\
\left(\times 10^{-10} \mathrm{~g}\right. \\
\left.\mathrm{mL}^{-1}\right)\end{array}$ & $\begin{array}{c}\text { Recovery } \\
(\%)\end{array}$ & $\begin{array}{c}\text { Average } \\
\text { recovery } \\
(\%)\end{array}$ \\
\hline $\begin{array}{l}\text { Human } \\
\text { serum 1 }\end{array}$ & 2.00 & $1.94 \pm 0.08$ & $97.0 \pm 4$ & \\
$\begin{array}{l}\text { Human } \\
\text { serum 2 }\end{array}$ & 2.00 & $2.12 \pm 0.04$ & $106.0 \pm 2$ & $103.3 \pm 3.7$ \\
$\begin{array}{l}\text { Human } \\
\text { serum 3 }\end{array}$ & 4.00 & $4.28 \pm 0.21$ & $107.0 \pm 5$ & \\
\hline AFP $=\alpha$-Fetoprotein & & & &
\end{tabular}

\section{Conclusion}

A simple, sensitive and antifouling impedimetric lectin biosensor for determination of $\alpha$-fetoprotein was developed by employing a binary monolayer, incorporating 11-mercaptoundecanoic acid as covalent immobilization of lectin and dithiothreitol as an interface resisting nonspecific interactions. The novel interface offers high sensitivity and direct measurement of picomole ( $\mathrm{pg} \mathrm{mL}^{-1}$ ) levels of target $\alpha$-fetoprotein in human serum with good antifouling characteristics. This work provides a promising strategy for real-world clinical application with impressive sensitivity and antifouling characteristics.

\section{ACKNOWLEDGEMENTS}

Financial supports from Technology Innovation Program of Ministry of Education of Shanxi Province of China (No. 2013151), the Science Foundation of Shanxi Province of China (No. 2012011007-1) and Doctoral Science Foundation of Yuncheng University (No. YKU2012018 and YKU2012019) are gratefully acknowledged.

\section{REFERENCES}

1. N.L. Anderson and N.G. Anderson, Mol. Cell. Proteomics, 1, 845 (2002).

2. G.E. Ritchie, B.E. Moffatt, R.B. Sim, B.P. Morgan, R.A. Dwek and P.M. Rudd, Chem. Rev., 102, 305 (2002).

3. R. Kannagi, M. Izawa, T. Koike, K. Miyazaki and N. Kimura, Cancer Sci., 95, 377 (2004).

4. Y. Li, H. Qi, Q. Gao and C. Zhang, Biosens. Bioelectron., 26, 2733 (2011).

5. Z.Y. Guo, T.T. Hao, J. Duan, S. Wang and D.Y. Wei, Talanta, 89, 27 (2012).

6. N. Gan, J.G. Hou, F.T. Hu, Y.T. Cao, T.H. Li, L. Zheng and J. Wang, Int. J. Electrochem. Sci., 6, 5146 (2011).

7. L. Wang and X.X. Gan, Mikrochim. Acta, 164, 231 (2009).

8. H.L. Qi, C. Ling, Q.Y. Ma, Q. Gao and C.X. Zhang, Analyst, 137, 393 (2011).

9. M. Giannetto, L. Elviri, M. Careri, A. Mangia and G. Mori, Biosens. Bioelectron., 26, 2232 (2011).

10. D. Du, Z.X. Zou, Y. Shin, J. Wang, H. Wu, M.H. Engelhard, J. Liu, I.A. Aksay and Y.H. Lin, Anal. Chem., 82, 2989 (2010).

11. J. Tang, B.L. Su, D.P. Tang and G.N. Chen, Biosens. Bioelectron., 25, 2657 (2010).

12. J. Tang, D.P. Tang, B.L. Su, Q.F. Li, B. Qiu and G.N. Chen, Analyst, 136, 3869 (2011)

13. Y.Q. Miao and J.G. Guan, Anal. Lett., 37, 1053 (2004).

14. Y.F. Chang, R.C. Chen, Y.J. Lee, S.C. Chao, L.C. Su, Y.C. Li and C. Chou, Biosens. Bioelectron., 24, 1610 (2009).

15. C.K. O'Sullivan, Anal. Bioanal. Chem., 372, 44 (2002).

16. H.L. Sharon, Glycobiology, 14, 53 (2004).

17. H. Tateno, S. Nakamura-Tsuruta and J. Hirabayashi, Glycobiology, 19, 527 (2009).

18. D. Clark and L. Mao, Dis. Markers, 33, 1 (2012).

19. R.R. Drake, E.E. Schwegler, G. Malik, J. Diaz, T. Block, A. Mehta and O.J. Semmes, Mol. Cell. Proteomics, 5, 1957 (2006).

20. S. Chen, T. LaRoche, D. Hamelinck, D. Bergsma, D. Brenner, D. Simeone, R.E. Brand and B. Haab Brian, Nat. Methods, 4, 437 (2007).

21. L. Ding, W. Cheng, X.J. Wang, Y.D. Xue, J.P. Lei, Y.B. Yin and H.X. Ju, Chem. Commun., 45, 7161 (2009).

22. J.T. La Belle, J.Q. Gerlach, S. Svarovsky and L. Joshi, Anal. Chem., 79, 6959 (2007).

23. Y. Li, S. Tao, G.S. Bova, A.Y. Liu, D.W. Chan, H. Zhu and H. Zhang, Anal. Chem., 83, 8509 (2011).

24. X. Li, L. Shen, D. Zhang, H. Qi, Q. Gao, F. Ma and C. Zhang, Biosens. Bioelectron., 23, 1624 (2008).

25. D.L.M. Oliveira, M.L. Nogueira, M.T.S. Correia, L.C.B.B. Coelho and C.A.S. Andrade, Sens. Actuators B, 155, 789 (2011).

26. T. Komatsu, Nanoscale, 4, 1910 (2012).

27. A. Bogomolova, E. Komarova, K. Reber, T. Gerasimov, O. Yavuz, S. Bhatt and M. Aldissi, Anal. Chem., 81, 3944 (2009).

28. A. Hucknall, S. Rangarajan and A. Chilkoti, Adv. Mater., 21, 2441 (2009). 
29. H. Qi, L. Shangguan, C. Li, X. Li, Q. Gao and C. Zhang, Biosens. Bioelectron., 39, 324 (2013).

30. B.T. Houseman and M. Mrksich, Angew. Chem. Int. Ed., 38, 782 (1999).

31. F. Frederix, K. Bonroy, W. Laureyn, G. Reekmans, A. Campitelli, W. Dehaen and G. Maes, Langmuir, 19, 4351 (2003).

32. L. Huang, G. Reekmans, D. Saerens, J.-M. Friedt, F. Frederix, L. Francis, S. Muyldermans, A. Campitelli and C.V. Hoof, Biosens. Bioelectron., 21, 483 (2005)

33. J.T. Gallagher, Biosci. Rep., 4, 621 (1984).

34. P. Chen, Y.K. Liu, X.N. Kang, L. Sun, P.Y. Yang and Z.Y. Tang, J. Cancer Res. Clin. Oncol., 134, 851 (2008).

35. A.R. MacDairmid, M.C. Gallagher and J.T. Banks, J. Phys. Chem. B, 107, 9789 (2003).
36. E.A. Smith, W.D. Thomas, L.L. Kiessling and R.M. Corn, J. Am. Chem. Soc., 125, 6140 (2003).

37. X. Jiang, A. Housni, G. Gody, P. Boullanger, M. Charreyre, T. Delair and R. Narain, Bioconjug. Chem., 21, 521 (2010).

38. F. St. Michael, E. Vinogradov, C.Q. Wenzel, B. McIntosh, J. Li, J.C. Hoe, J.C. Richards and A.D. Cox, Glycobiology, 19, 633 (2009).

39. S. Szunerits, J. Niedziolka-Jonsson, R. Boukherroub, P. Woisel, J.S. Baumann and A. Siriwardena, Anal. Chem., 82, 8203 (2010).

40. T. Fukuda, S. Onogi and Y. Miura, Thin Solid Films, 518, 880 (2009).

41. T. Bertok, L. Klukova, A. Sediva, P. Kasak, V. Semak, M. Micusik, M. Omastova, L. Chovanova, M. Vlcek, R. Imrich, A. Vikartovska and J. Tkac, Anal. Chem., 85, 7324 (2013).

42. M. Song, Y. Zhang, T. Li, Z. Wang, J. Yin and H. Wang, J. Chromatogr. A, 1216, 873 (2009). 